\title{
Study of the Etiological Causes of Toe Web Space Lesions in Cairo, Egypt
}

\author{
Hussein Mohamed Hassab-El-Naby, ${ }^{1,2}$ Yasser Fathy Mohamed, ${ }^{1,2}$ \\ Hamed Mohamed Abdo, ${ }^{1,2}$ Mohamed Ismail Kamel, ${ }^{1,2}$ \\ Wael Refaat Hablas, ${ }^{1,3}$ and Osama Khalil Mohamed ${ }^{1,2}$ \\ ${ }^{1}$ Al-Hussein University Hospital, Gawhar Al Qaed Street, El Darrasa, Cairo 11633, Egypt \\ ${ }^{2}$ Dermatology, Venereology and Andrology, Faculty of Medicine, Al-Azhar University, Cairo 11823, Egypt \\ ${ }^{3}$ Clinical and Chemical Pathology, Faculty of Medicine, Al-Azhar University, Cairo 11823, Egypt \\ Correspondence should be addressed to Hamed Mohamed Abdo; hamed392@yahoo.com
}

Received 11 July 2015; Revised 6 September 2015; Accepted 7 September 2015

Academic Editor: Iris Zalaudek

Copyright (C) 2015 Hussein Mohamed Hassab-El-Naby et al. This is an open access article distributed under the Creative Commons Attribution License, which permits unrestricted use, distribution, and reproduction in any medium, provided the original work is properly cited.

\begin{abstract}
Background. The etiology of foot intertrigo is varied. Several pathogens and skin conditions might play a role in toe web space lesions. Objective. To identify the possible etiological causes of toe web space lesions. Methods. 100 Egyptian patients were enrolled in this study (72 females and 28 males). Their ages ranged from 18 to 79 years. For every patient, detailed history taking, general and skin examinations, and investigations including Wood's light examination, skin scraping for potassium hydroxide test, skin swabs for bacterial isolation, and skin biopsy all were done. Results. Among the 100 patients, positive Wood's light fluorescence was observed in 24 and positive bacterial growth was observed in 85. With skin biopsy, 52 patients showed features characteristic for eczema, 25 showed features characteristic for fungus, 19 showed features characteristic for callosity, and 3 showed features characteristic for wart while in only 1 patient the features were characteristic for lichen planus. Conclusion. Toe web space lesions are caused by different etiological factors. The most common was interdigital eczema (52\%) followed by fungal infection (25\%). We suggest that patients who do not respond to antifungals should be reexamined for another primary or secondary dermatologic condition that may resemble interdigital fungal infection.
\end{abstract}

\section{Introduction}

Toe web intertrigo may present as a relatively asymptomatic, mild scaling but it also can be seen as a painful, exudative, macerated, erosive, inflammatory process which is sometimes malodorous [1].

Foot intertrigo is mostly caused by dermatophytes and yeasts and less frequently by Gram-negative and Grampositive bacteria. Gram-negative infection is relatively common and may represent a secondary infection of tinea pedis. With time, a "complex" may develop in the setting of moisture and maceration that contains multiple fungal and bacterial organisms [2,3]. Frequently, these interdigital lesions are often diagnosed as tinea pedis or eczematous dermatitis. However, in some patients, the macerated eruption is unresponsive to treatment with antifungal agents or antiinflammatory agents such as topical steroids [4].

Other less common conditions may also affect the web space such as erythrasma [5]. Because the texture of soft corn is macerated, it may be misdiagnosed clinically as a mycotic infection of the interdigital space [6]. Interdigital psoriasis ("white psoriasis" or "psoriasis alba") is a distinct but atypical form of psoriasis that is often missed as it is commonly mistaken for interdigital fungal infection [7]. A report of Bowen's disease [8] and a case of Verrucous carcinoma in the third and fourth toe web space which is presented by intractable intertrigo has been reported [9]. Also, malignant melanoma in the interdigital space has been diagnosed [10].

It is apparent that several pathogens and factors might play a role in toe web space lesions. Therefore, clinical and 
microbiologic studies are suggested to assist in the selection of appropriate treatment and the prevention of important complications [3]. In this study, we aimed to determine the different etiological causes of pedal web space lesions.

\section{Patients and Methods}

This study included 100 Egyptian patients living in Cairo who presented at Dermatology Departments of Al-Azhar University Hospitals with toe web space lesions. The study was approved by the Al-Azhar University Medical Ethics Committee, and written prior informed consent was obtained from every participant. Patients who have received systemic and/or topical antifungal and/or antibiotic treatments in the past 6 weeks were excluded.

Every patient was subjected to the following: (1) full history taking; (2) general and local examinations; (3) Wood's light examination for possible fluorescence; (4) skin scraping for direct potassium hydroxide $(\mathrm{KOH})$ test: scraping of lesions was done with a blunt scalpel then a drop of $20 \% \mathrm{KOH} / 40 \%$ dimethyl sulfoxide (DMSO) mixture was added to the specimen (DMSO increases sensitivity of the preparation and softens keratin more quickly than $\mathrm{KOH}$ alone in the absence of heat [11]); the slide was then examined for fungus using low power field $\times 10$ then high power field $\times 40$; (5) skin swabs for bacterial isolation: cotton swabs were taken from the lesions and incubated for 24 hours at $37^{\circ} \mathrm{C}$ in blood and MacConkey (BIOTEC Lab. Ltd., UK) and nutrient (Oxoid Ltd., England) agars; the bacterial cultures were considered negative if there was no growth after 48 hours of incubation; the suspected colony was picked up for morphological and biochemical reactions for their identifications; (6) a $3 \mathrm{~mm}$ punch biopsy was taken from the lesion. Specimens were fixed in 10\% formalin then sectioned and stained with haematoxylin and eosin stain (as a routine) and PAS stain (to highlight fungal elements).

All involved toe web spaces were examined with Wood's light while $\mathrm{KOH}$ test, skin swabs for bacterial isolation, and skin biopsy were done from the most affected web space showing intensive erythema and desquamation (almost the 4 th web space). Wood's light examination aimed to show the characteristic coral red fluorescence with erythrasma [12].

The goal of mycological workup in this study was to demonstrate just the presence of fungi (regardless of its nature) as an etiologic cause of web space lesions; so we thought that $\mathrm{KOH}$ test (supported by PAS-stained tissue sections) will suffice this aim. The recognition of fungal organisms as dermatophyte, mould, or yeast by $\mathrm{KOH}$ is presumptive although it is highly probable [13]. We relied upon the WHO guidelines on standard operating procedures for microbiology [14]. These guidelines document that dermatophyte has regular, small hyphae $(2-3 \mu \mathrm{m})$ with some branching, sometimes with rectangular arthrospores. Candida has hyphae/pseudohyphae (with distinct points of constriction) with budding yeast forms. Aspergillus species had hyphae that are usually small $(3-6 \mu \mathrm{m})$ and regular in size, dichotomously branching at 45-degree angles with distinct cross septa.
The histopathological examination aimed to correlate with and confirm the clinical diagnosis. A diagnosis of lichen planus is established when the biopsy showed the following criteria: dense, band-like infiltrate of lymphocytes that is strictly confined to the subepidermal area. The lymphocytes attack and destroy the basic part of the epidermis, giving rise to characteristic sawtooth like rete ridges. The cell infiltrate in the dermis consists of lymphocytes with a mixture of some mast cells and macrophages; there is also a variable amount of melanin pigment which has leaked from the injured epidermis. There are no plasma cells or eosinophils [15].

In biopsies stained with PAS, fungal elements are highlighted, with hyphae and spores stained red. Dermatophytes produce septate hyphae and arthrospores [15].

Biopsy from patients with eczema demonstrates that epidermis shows moderate to marked acanthosis and hyper/ parakeratosis. There may be areas of inter- and intracellular edema and rarely scattered small vesicles. The inflammatory cell infiltrates mainly consist of lymphocytes. Edema in the dermis is not prominent. Sometimes the pattern is psoriasislike and shows long, slender rete ridges and papillae, which are covered by thin epidermis and contain thin-walled dilated venules filled with erythrocytes [15].

Acanthosis, papillomatosis, and hyperkeratosis are observed in biopsies from patients with warts, with confluence of the epidermal ridges in the centre of the lesion and koilocytes [16].

A thickened compact stratum corneum with slight cupshaped depression of the underlying epidermis is seen in patients with callosity. The granular layer, in contrast to corn, may be thickened. There may be some parakeratosis overlying the dermal papillae, but much less than in a corn [17].

\section{Results}

3.1. Demographic and Clinical Findings. Of 100 patients with toe web space lesions, 72 were females and 28 were males. Their ages ranged from 18 to 79 years (mean 43.94 years; $\mathrm{SD} \pm 14.94$ ). Regarding the presenting symptoms, 64 patients complained of pruritus while only 2 complained of pain and 34 were asymptomatic. The 4 th web space was the commonest space affected in both right and left feet, followed by 3 rd space, 2 nd space, and 1st space $(79 \%, 62 \%, 33 \%$, and $7 \%$ versus $76 \%, 63 \%, 30 \%$, and $8 \%$, resp.) (Table 1 ). Of the 100 patients, 8 patients had lesion in 1 web space, 21 had lesion in 2 web spaces, 26 had lesion in 3 web spaces, 17 had lesion in 4 web spaces, 6 had lesion in 5 web spaces, 18 had lesion in 6 web spaces, 1 had lesion in 7 toe web spaces, and 3 had lesion in 8 web spaces.

3.2. Wood's Light Examination. Among the 100 patients, positive Wood's light fluorescence was observed in 24; of them, 20 were females and 4 were males. All revealed coral red fluorescence characteristic for erythrasma.

3.3. Microbiological Findings. Positive $\mathrm{KOH}$ results were noticed in 66 patients; 50 were females and 16 were males. $57 \mathrm{KOH}$ mounts were highly typical of yeast species (yeast 
TABLE 1: Distribution of toe web space lesions in the 100 patients.

\begin{tabular}{lcccc}
\hline \multirow{2}{*}{ Toe web space } & \multicolumn{2}{c}{ Right foot } & \multicolumn{2}{c}{ Left foot } \\
& Frequency & $\%$ & Frequency & $\%$ \\
\hline 1st space & 7 & 7.0 & 8 & 8.0 \\
2nd space & 33 & 33.0 & 30 & 30.0 \\
3rd space & 62 & 62.0 & 63 & 63.0 \\
4th space & 79 & 79.0 & 76 & 76.0 \\
\hline
\end{tabular}

cells alone or with pseudohyphae with distinct points of constrictions) while 9 were typical of mold/dermatophytes (arthrospores and hyphae of uniform diameter). Positive bacterial growth was observed in 85 patients ( 64 females and 21 males). These were $47 \mathrm{Gram}$-positive cocci (36 females and 11 males) and 38 Gram-negative bacilli (28 females and 10 males) (Table 2). No combined presence of Gram-positive cocci and Gram-negative bacilli was detected in any case but both were associated with other microbial and nonmicrobial states.

3.4. Histopathological Findings. Of the 100 skin biopsy sections, 52 (40 females and 12 males) showed features characteristic for eczema (Figure 1), 25 (20 females and 5 males) showed features characteristic for fungus (Figure 2), $\mathrm{KOH}$ was also positive in 22 of these patients (18 yeasts and 4 dermatophytes), 19 (10 females and 9 males) showed features characteristic for callosity (Figure 3 ), 3 (2 males and 1 female) showed features characteristic for wart (Figure 4), and only 1 section (female) showed features characteristic for lichen planus (Figure 5) (Table 3).

Most of the patients showed more than one etiological factor for the intertrigo. 50 cases presented with 2 diseases, 38 cases presented with 3 diseases, 9 cases presented with 4 diseases, and only 3 patients showed a single disease. Positive Wood's light fluorescence (erythrasma) was associated with $14 \mathrm{KOH}$-positive cases, 15 cases with Gram-positive cocci, 6 cases with Gram-negative bacilli, 12 cases with biopsy proven eczema, 8 cases with biopsy proven fungus, and 3 cases with biopsy proven callosity. Gram-positive cocci were associated with $36 \mathrm{KOH}$-positive cases, 15 positive Wood's light fluorescence (erythrasma) cases, 10 biopsy proven fungi, 26 eczema cases, 6 callosities, and 1 wart. Gram-negative bacilli were associated with $22 \mathrm{KOH}$-positive cases, 6 positive Wood's light fluorescence (erythrasma) cases, 11 biopsy proven fungi, 20 eczema cases, 7 callosities, and 1 lichen planus.

\section{Discussion}

Foot intertrigo may present as a chronic erythematous desquamative eruption. This is often diagnosed as tinea pedis or eczematous dermatitis. However, in some patients, the macerated eruption is unresponsive to treatment with antifungals or anti-inflammatory agents [4]. Therefore, clinical and microbiological studies are suggested to assist in the selection of appropriate treatment and the prevention of important complications [3]. This study was planned to verify the etiological causes of toe web space lesions in randomly
TABle 2: Microbiological findings in the 100 patients.

\begin{tabular}{lccc}
\hline & Positive KOH mount & \multicolumn{2}{c}{ Positive bacterial cultures } \\
& & G+ve cocci & G-ve bacilli \\
\hline Female & 50 & 36 & 28 \\
Male & 16 & 11 & 10 \\
Total & 66 & 47 & 38 \\
$\%$ & 66.0 & 47.0 & 38.0 \\
\hline
\end{tabular}

TABLE 3: Frequency of histological diagnosis among the 100 patients.

\begin{tabular}{lcccc}
\hline \multirow{2}{*}{$\begin{array}{l}\text { Histopathological } \\
\text { diagnosis }\end{array}$} & \multicolumn{2}{c}{ Frequency } & Total & $\%$ \\
\hline Eczema & 40 & 12 & 52 & 52.0 \\
Fungus & 20 & 5 & 25 & 25.0 \\
Callosity & 10 & 9 & 19 & 19.0 \\
Wart & 1 & 2 & 3 & 3.0 \\
Lichen planus & 1 & 0 & 1 & 1.0 \\
Total & 72 & 28 & 100 & 100.0 \\
\hline
\end{tabular}

selected 100 Egyptian patients. All of the patients were adults between 18-79 years of age (mean 43. $94 \mathrm{yrs}$ ). This is in agreement with other similar reports $[18,19]$.

In our study, 72 (72\%) were females; the majority of them were housewives. Household work including kitchen work, duties for cleaning, washing, caring for children and other domestic activities, and shopping may explain the increased incidence of microbial intertrigo especially tinea pedis in this sector of population. On the contrary, Ahmad et al. [19] in Pakistan reported higher rate in males (56.7\%). They attributed this to wearing closed shoes most of the time in hot and humid climate. In our patients, the 4th (lateral) toe web space was the most commonly affected in both right (79\%) and left $(76 \%)$ foot. This is in agreement with several reports [18-20]. This could be related to anatomical considerations (potentially occluded space).

Many authors refer to web space infection as tinea pedis or "foot ringworm" and some consider it to be purely dermatophytes induced [21-23]. However, other studies have demonstrated that recovery of dermatophytes from macerated webs is low. Generally, it ranges from $7.5 \%$ to $61 \%$ [1, 24-26]. The lower incidence of dermatophyte infection in these studies may be explained by the fact that, in mixed intertrigo, bacterial production of methanethiol and other sulfur compounds can lead to inhibition of dermatophytes [1].

Depending on $\mathrm{KOH}$ mount, this study showed that tinea pedis was observed in $66(66 \%)$ patients; 50 of them were females $(75.76 \%)$ and 16 were males $(24.24 \%)$. This agrees with Morales-Trujillo et al. [5] who declared that fungi were positive in $62.5 \%$ of 70 cases. Using $\mathrm{KOH}$, Ahmad et al. [19] out of 118 cases reported higher rate of positivity where $90 \%$ had positive direct microscopy while only $50.8 \%$ had positive cultures. On the other hand, Pau et al. [27] in a study on 1568 patients reported lower rate of tinea pedis infection (14.79\%). This disagreement may be due to difference in life styles (e.g., 

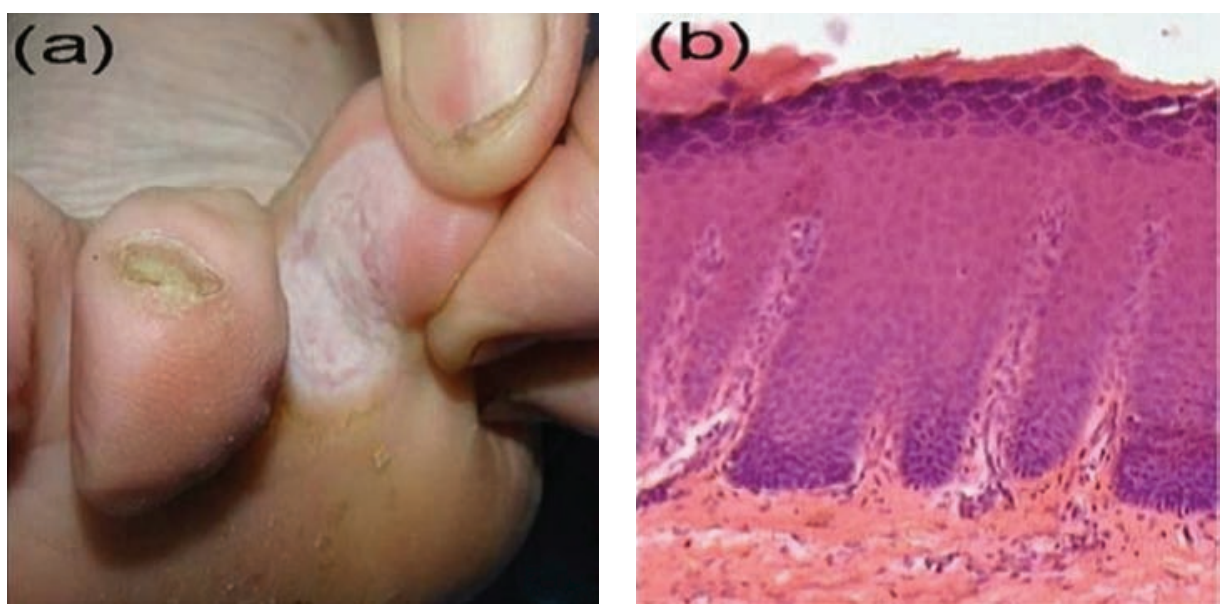

FIGURE 1: Interdigital eczema. (a) Interdigital whitish plaque with an ill-defined border. (b) Histopathological features of subacute spongiotic dermatitis (H\&E, $\times 100)$.
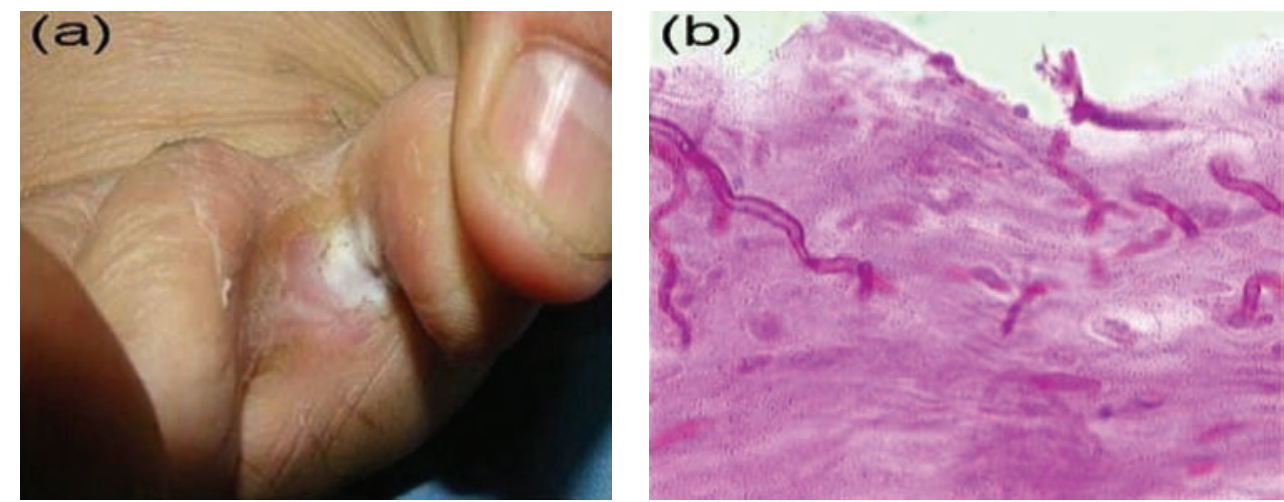

FIGURE 2: Interdigital fungal intertrigo. (a) Interdigital whitish plaques with macerated, sodden skin. (b) Biopsy from the lesion showing fungal pseudohyphae in the stratum corneum (PAS, $\times 400)$.
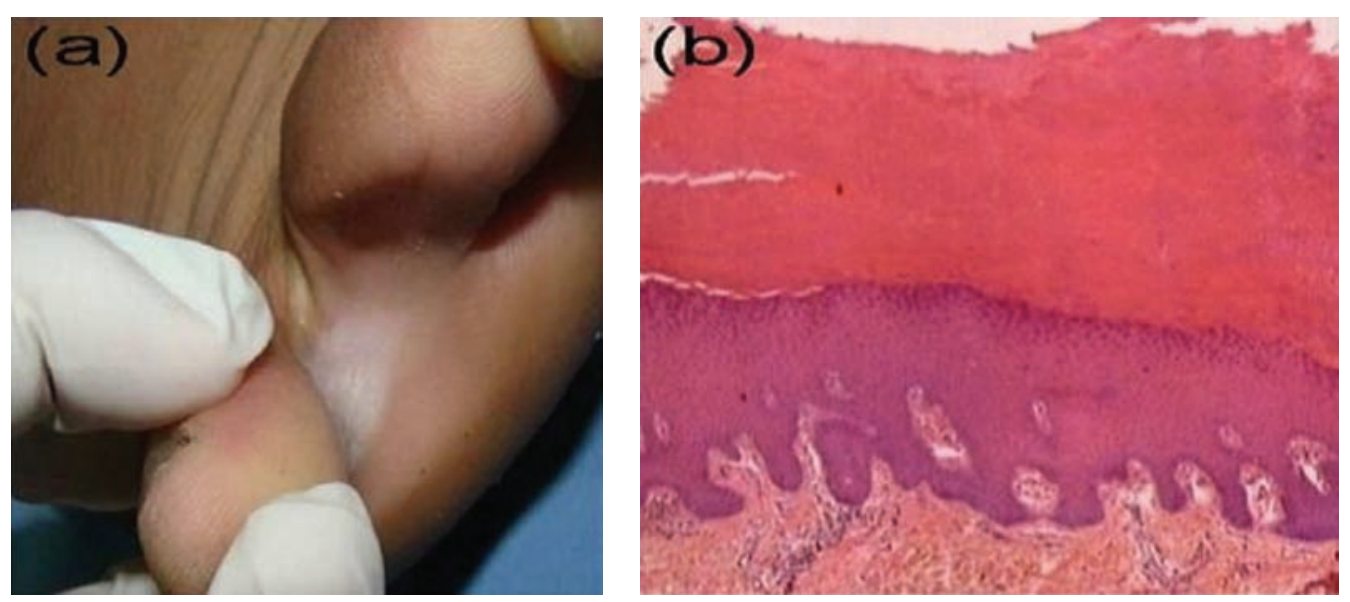

FIGURE 3: Interdigital callosity. (a) Interdigital whitish plaque with well-defined border. (b) Histopathological picture showing compact hyperkeratosis and moderate acanthosis $(\mathrm{H} \& \mathrm{E}, \times 100)$. 

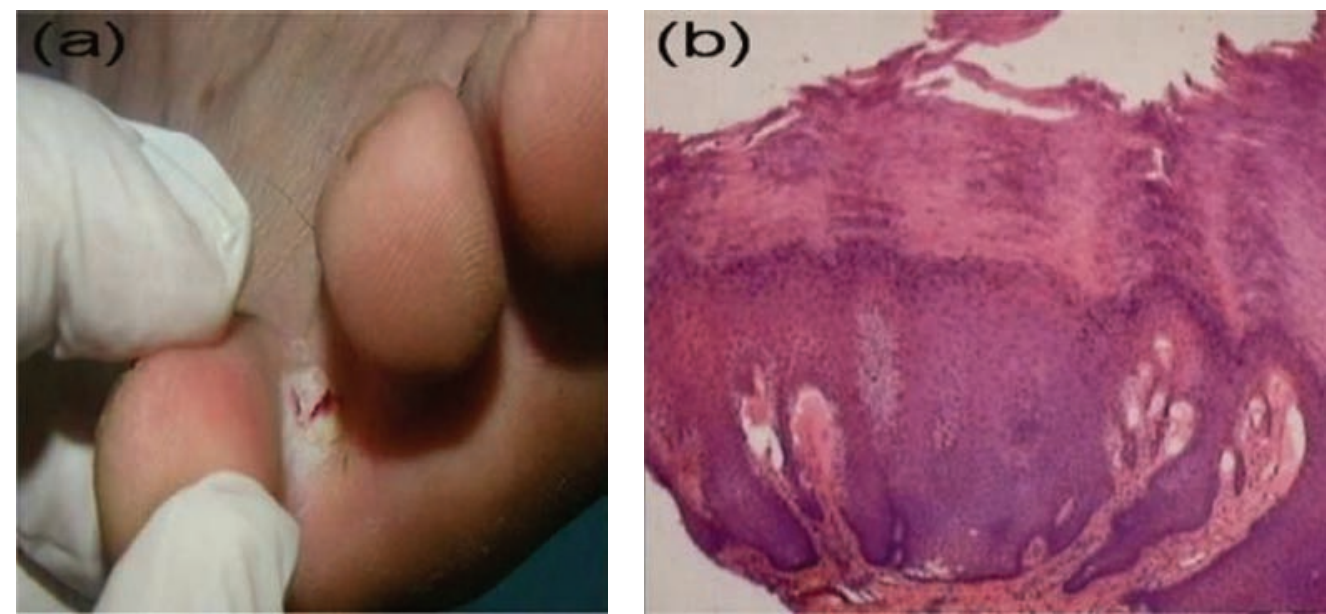

FIGURE 4: Interdigital wart. (a) Interdigital whitish plaque with well-defined border. (b) The punch biopsy shows changes characteristic for a common wart $(\mathrm{H} \& \mathrm{E}, \times 100)$.
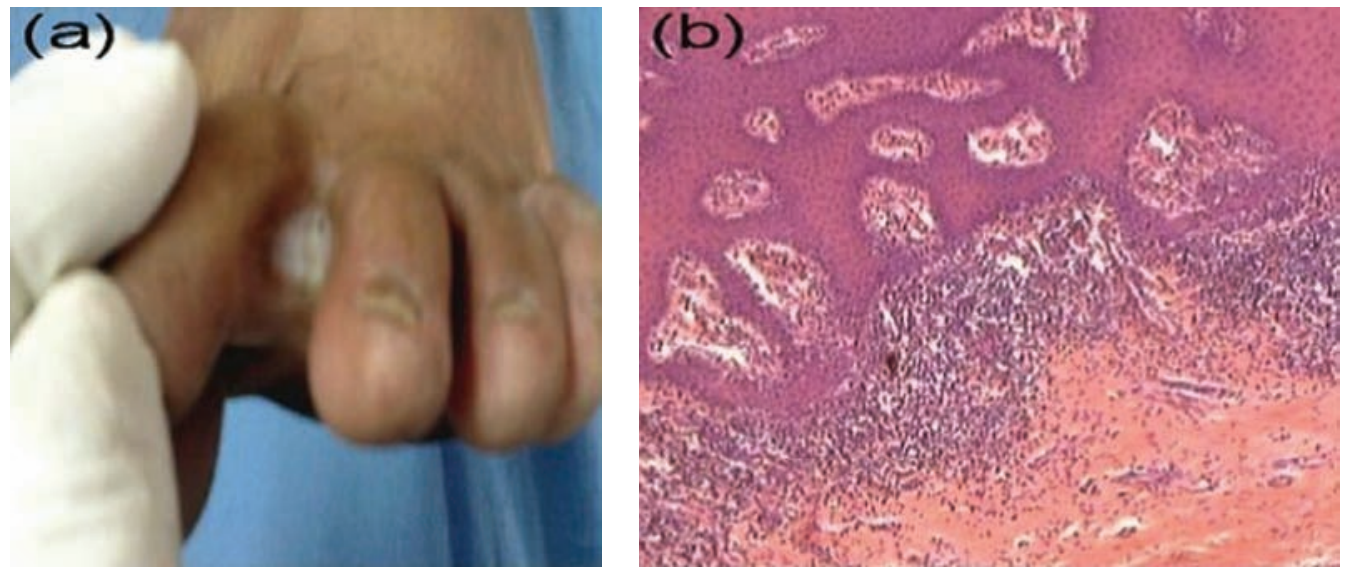

Figure 5: Interdigital lichen planus. (a) Interdigital whitish plaque with well-defined border. (b) The biopsy shows acanthosis, band-like lymphocytic infiltrate in the papillary dermis and vacuolar alteration of basal cell layer $(\mathrm{H} \& \mathrm{E}, \times 100)$.

type of shoes worn), weather conditions such as humidity, and the varying number of cases in each study.

Cases with erythrasma can be diagnosed by positive Wood's lamp examination and/or Gram staining/culture [28]. In the present study, positive coral red fluorescence with Wood's light, which is characteristic for erythrasma, was found in $24 \%$ of the patients. The prevalence of erythrasma varies greatly from one study to another. Sariguzel et al. [29] reported a prevalence of $19.6 \%$ in 121 patients with interdigital foot lesions. Allen et al. [30] reported that, in 300 patients, $18.7 \%$ were determined to have erythrasma. Morales-Trujillo et al. [5] examined 73 patients, of whom 24 (32.8\%) were diagnosed with erythrasma. Inci et al. [28] concluded that the rate of erythrasma was found to be $46.7 \%$ among 122 patients with interdigital foot lesions. Svejgaard et al. [31] reported a prevalence of $51.3 \%$, (prior to military service) and $77.1 \%$ (reexamined at the end of military service) in a group of Danish military recruits.

This discrepancy may be attributed to the type of population studied, environmental conditions such as heat and humidity that increased the risk for developing erythrasma, and the methods used in diagnosis, for example, Wood's light examination, culture, and/or direct microscopy with Gram staining. In Polat and İlhan [32] study, using only Wood's lamp examination or Gram's staining resulted in 31 (42.5\%) or $14(19.2 \%)$ positive patients, respectively. Using Wood's lamp examination and Gram's staining concurrently resulted in 28 positive patients (38.4\%). Interestingly, Inci et al. [28] reported no growth for C. minutissimum in bacteriological cultures from all patients with interdigital lesions. However, they found that using only Wood's lamp examination or Gram staining resulted in 11 (9\%) and 19 positive patients (15.6\%), respectively, whereas using both Wood's lamp examination and Gram staining concurrently resulted in 27 positive patients $(22.1 \%)$. This suggests that bacteriological cultures have no or limited role in diagnosing erythrasma.

In this study, interdigital erythrasma was demonstrated more in females $(83.3 \%)$ than males (16.7\%). This finding agrees with Morales-Trujillo et al. [5] who stated that interdigital erythrasma was more common in women than men 
(83.3\% versus 16.7\%). Also, Polat and İlhan [32] stated that most of their patients with erythrasma were women (56.2\%). The exact cause of this female predominance is unknown but may be attributed to occupational factors including household duties and exposure to more heat and humidity.

The interdigital space is typically colonized by polymicrobial flora. Dermatophytes may damage the stratum corneum and produce substances with antibiotic properties. Gramnegative bacteria may resist antibiotic-like substances and proliferate. This process may progress to Gram-negative foot intertrigo [4]. In this study, no combined presence of Grampositive cocci and Gram-negative bacilli was detected in any case. Although the lack of this association is unreasonable, it could not be exactly explained. Gram-positive cocci were associated with $36 \mathrm{KOH}$ and 10 biopsy proven fungi. Gram-negative bacilli were associated with $22 \mathrm{KOH}$ and 11 biopsy proven fungi. Gram-negative bacterial infection may represent a secondary invasion of web space lesions. With time, in the presence of local humidity and maceration, other Gram-positive bacterial (and fungal) organisms may proliferate. So, the web space infection may represent a single or polymicrobial etiology.

Based on bacterial cultures, 47 patients (47\%) were harboring Gram-positive cocci, while 38 (38\%) were harboring Gram-negative bacilli. This agrees with Karaca et al. [3] who concluded that the most common pathogen was Grampositive cocci (17.9\%), followed by $P$. aeruginosa $(16.7 \%)$. Also the bacteria isolated by Ahmad et al. [19] were $S$. aureus (Gram-positive cocci) in $83.4 \%$, P. aeruginosa in $10 \%$, Proteus spp. in 3.3\%, and $\beta$-hemolytic streptococci in $3.3 \%$ (Gram-negative bacteria). This disagrees with Aste et al. [2] who concluded that $P$. aeruginosa was found to be the prevailing pathogen, both alone and associated with other Gram-negative bacteria (such as E. coli, Proteus mirabilis, and Morganella morganii) and Gram-positive bacteria.

Twenty-eight females were suffering from Gram-negative bacterial web space lesion versus only 10 males with female to male ratio 2.8:1. This disagrees with Aste et al. [2] who reported that Gram-negative interweb foot infection represents a male-to-female ratio of $4: 1$. Also Lin et al. [4] reported that foot bacterial intertrigo was more common in men $(82 \%)$. The more prevalence in male gender can be related to the more frequent use of closed shoes for occupational and nonoccupational activities such as during the practice of sports.

Generally speaking, the routine diagnosis of interdigital lesions depends mainly upon history and clinical appearance with or without the need for direct microscopy of a $\mathrm{KOH}$ preparation, bacterial cultures, and/or Wood's light examination while web space biopsy is not routinely used. Yet this study declared the additional value of web space histopathology with clinical correlation in definitive diagnosis of interdigital lesions.

Despite the great clinical similarities, after clinicopathological correlations, we have diagnosed a lot of cases of interdigital eczema (52\% of cases). These were clinically manifested as pruritic macerated glazed skin usually limited to the interdigital space. PAS-positive cases (interdigital fungal intertrigo) which constituted $25 \%$ of cases were clinically presented as pruritic, wet, and macerated interdigital space which usually extended to the plantar and/or dorsal surface of the foot. Some cases were associated with fungal infection of other parts of the body. Cases of callosity of toe web space (19\%) were characterized by a well-defined white plaque limited to the web space. Three cases of interdigital warts were diagnosed (3\%): two cases were asymptomatic while the third case was complaining of painful lesion. All of the 3 cases were associated with planter warts.

In this study, we found a healthy 49-year-old female clinically presented with pruritic interdigital lesions of 3 weeks' duration. Examination revealed bilateral and symmetrical whitish ill-defined plaques in the second and the third web spaces of both feet. Biopsy was characteristic for lichen planus. This is a very rare site for lichen planus. We think that it is important to recall such underestimated variant of lichen planus and other uncommon dermatoses in this site.

\section{Conclusion}

Many cases of web space lesions can be overdiagnosed, underdiagnosed, or misdiagnosed. These may be caused by different conditions including eczema, fungal intertrigo, erythrasma, callosity, wart, or even lichen planus. Although fungal foot infection is common, we suggest that patients who do not respond to topical and/or systemic antifungal therapy should be reexamined for another primary or secondary dermatologic condition that may resemble pedal fungal intertrigo. The diagnostic procedures in this work can be complementary to each other and can be used as an investigative workup tailored to individual patients who have resistant to treat or have atypical interdigital lesions.

\section{Conflict of Interests}

The authors declare that there is no conflict of interests regarding the publication of this paper.

\section{References}

[1] J. L. Leyden, "Tinea pedis pathophysiology and treatment," Journal of the American Academy of Dermatology, vol. 31, no. 3, part 2, pp. S31-S33, 1994.

[2] N. Aste, L. Atzori, M. Zucca, M. Pau, and P. Biggio, "Gramnegative bacterial toe web infection: a survey of 123 cases from the district of Cagliari, Italy," Journal of the American Academy of Dermatology, vol. 45, no. 4, pp. 537-541, 2001.

[3] S. Karaca, M. Kulac, Z. Cetinkaya, and R. Demirel, "Etiology of foot intertrigo in the district of Afyonkarahisar, Turkey: a bacteriologic and mycologic study," Journal of the American Podiatric Medical Association, vol. 98, no. 1, pp. 42-44, 2008.

[4] J.-Y. Lin, Y.-L. Shih, and H.-C. Ho, "Foot bacterial intertrigo mimicking interdigital tinea pedis," Chang Gung Medical Journal, vol. 34, no. 1, pp. 44-49, 2011.

[5] M. L. Morales-Trujillo, R. Arenas, and S. Arroyo, "Interdigital erythrasma: clinical, epidemiologic, and microbiologic findings," Actas Dermo-Sifiliográficas, vol. 99, no. 6, pp. 469-473, 2008. 
[6] R. K. Snider, "Corns and calluses," in Essentials of Musculoskeletal Care, W. B. Greene, Ed., pp. 437-441, American Academy of Orthopaedic Surgeons, Rosemont, Ill, USA, 2nd edition, 2001.

[7] J. M. R. Mommers, M. M. B. Seyger, C. J. M. van der Vleuten, and P. C. M. van de Kerkhof, "Interdigital psoriasis (psoriasis alba): renewed attention for a neglected disorder," Journal of the American Academy of Dermatology, vol. 51, no. 2, pp. 317-318, 2004.

[8] G. T. Liu, M. O. Lovell, and J. S. Steinberg, "Digital syndactylization for the treatment of interdigital squamous cell carcinoma in situ (Bowen disease)," Journal of Foot and Ankle Surgery, vol. 43, no. 6, pp. 419-422, 2004.

[9] C. McKay, P. McBride, and J. Muir, "Plantar verrucous carcinoma masquerading as toe web intertrigo," Australasian Journal of Dermatology, vol. 53, no. 2, pp. e20-e22, 2012.

[10] O. M. Rashid, J. C. Schaum, L. G. Wolfe, N. K. Brinster, and J. P. Neifeld, "Prognostic variables and surgical management of foot melanoma: review of a 25-year institutional experience," ISRN Dermatology, vol. 2011, Article ID 384729, 8 pages, 2011.

[11] N. Zaias, B. Glick, and G. Rebell, "Diagnosing and treating onychomycosis," The Journal of Family Practice, vol. 42, no. 5, pp. 513-518, 1996.

[12] P. Asawanonda and C. R. Taylor, "Wood's light in dermatology," International Journal of Dermatology, vol. 38, no. 11, pp. 801-807, 1999.

[13] H. W. Walling, "Subclinical onychomycosis is associated with tinea pedis," British Journal of Dermatology, vol. 161, no. 4, pp. 746-749, 2009.

[14] World Health Organization, "Mycological techniques," in Guidelines on Standard Operating Procedures for Microbiology, chapter 21, World Health Organization, Regional Office for South-East Asia, New Delhi, India, 2000, http://apps.searo.who .int/PDS_DOCS/B0217.pdf?ua=1.

[15] E. Brehmer-Andersson, Ed., Dermatopathology, Springer, Berlin, Germany, 1st edition, 2006.

[16] L. Requena and C. Requena, "Histopathology of the more common viral skin infections," Actas Dermo-Sifiliograficas, vol. 101, no. 3, pp. 201-216, 2010.

[17] J. W. Patterson, Ed., Weedon's Skin Pathology: Expert Consult, Elsevier Health Sciences, 4th edition, 2014.

[18] G. D. Masri-Fridling, "Dermatophytosis of the feet," Dermatologic Clinics, vol. 14, no. 1, pp. 33-40, 1996.

[19] S. Ahmad, S. Aman, I. Hussain, and T. S. Haroon, "A clinicoetiological study of toe web fungal infection," Journal of Pakistan Association of Dermatologists, vol. 13, no. 4, pp. 62-66, 2003.

[20] A. G. Martin and G. S. Kobayashi, "Superficial fungal infection," in Dermatology in General Medicine, I. M. Freedberg, A. Z. Eisen, K. Wolff et al., Eds., pp. 2337-2357, McGraw-Hill, New York, NY, USA, 5th edition, 1999.

[21] J. J. Leyden and A. M. Kligman, "Interdigital athlete's foot: new concepts in pathogenesis," Postgraduate Medicine, vol. 61, no. 6, pp. 113-116, 1977.

[22] A. K. Gupta, A. R. Skinner, and E. A. Cooper, "Interdigital tinea pedis (dermatophytosis simplex and complex) and treatment with ciclopirox $0.77 \%$ gel," International Journal of Dermatology, vol. 42, supplement 1, pp. 23-27, 2003.

[23] M. Al Hasan, S. M. Fitzgerald, M. Saoudian, and G. Krishnaswamy, "Dermatology for the practicing allergist: tinea pedis and its complications," Clinical and Molecular Allergy, vol. 2, article 5, 2004.
[24] J. J. Leyden and A. M. Kligman, "Interdigital Athlete's foot: interaction of dermatophytes and resident bacteria," Archives of Dermatology, vol. 114, no. 10, pp. 1466-1472, 1978.

[25] S. G. Kates, K. M. Nordstrom, K. J. McGinley, and J. J. Leyden, "Microbial ecology of interdigital infections of toe web spaces," Journal of the American Academy of Dermatology, vol. 22, no. 4, pp. 578-582, 1990.

[26] N. El Fekih, I. Belghith, S. Trabelsi, H. Skhiri-Aounallah, S. Khaled, and B. Fazaa, "Epidemiological and etiological study of foot mycosis in Tunisia," Actas Dermo-Sifiliograficas, vol. 103, no. 6, pp. 520-524, 2012.

[27] M. Pau, L. Atzori, N. Aste, R. Tamponi, and N. Aste, "Epidemiology of Tinea pedis in Cagliari, Italy," Giornale Italiano di Dermatologia e Venereologia, vol. 145, no. 1, pp. 1-5, 2010.

[28] M. Inci, G. Serarslan, B. Ozer et al., "The prevalence of interdigital erythrasma in southern region of Turkey," Journal of the European Academy of Dermatology and Venereology, vol. 26, no. 11, pp. 1372-1376, 2012.

[29] F. M. Sariguzel, A. Nedret Koc, G. Yagmur, and E. Berk, "Interdigital foot infections: Corynebacterium minutissimum and agents of superficial mycoses," Brazilian Journal of Microbiology, vol. 45, no. 3, pp. 781-784, 2014.

[30] S. Allen, T. I. Christmas, W. McKinney, D. Parr, and G. F. Oliver, "The Auckland skin clinic tinea pedis and erythrasma study," The New Zealand Medical Journal, vol. 103, no. 896, pp. 391-393, 1990.

[31] E. Svejgaard, J. Christophersen, and H. M. Jelsdorf, “Tinea pedis and erythrasma in Danish recruits. Clinical signs, prevalence, incidence, and correlation to atopy," Journal of the American Academy of Dermatology, vol. 14, no. 6, pp. 993-999, 1986.

[32] M. Polat and M. N. İlhan, "The prevalence of interdigital erythrasma-a prospective study from an outpatient clinic in Turkey," Journal of the American Podiatric Medical Association, vol. 105, no. 2, pp. 121-124, 2015. 


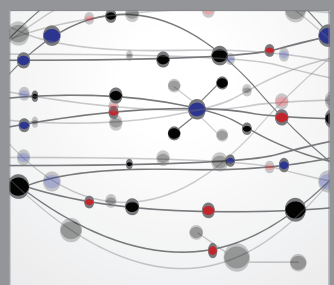

The Scientific World Journal
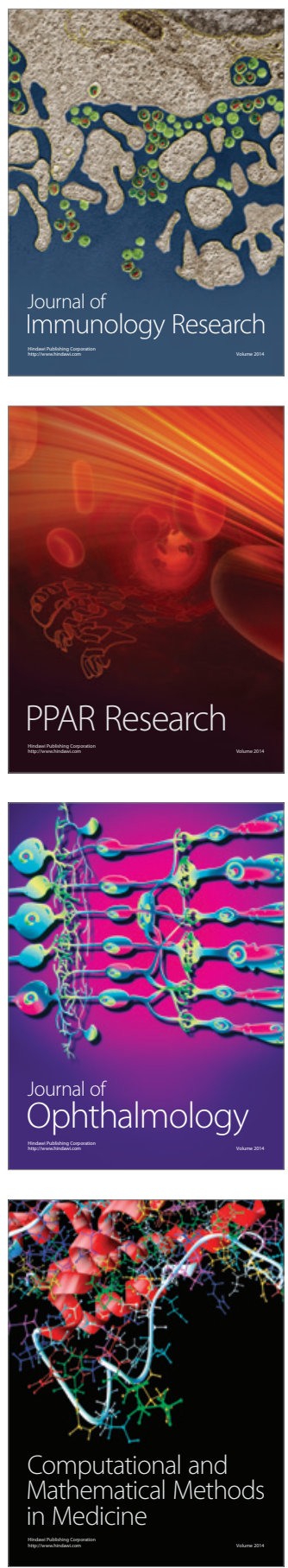

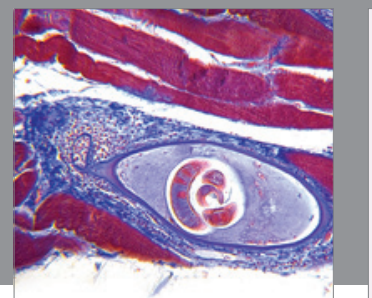

Gastroenterology

Research and Practice
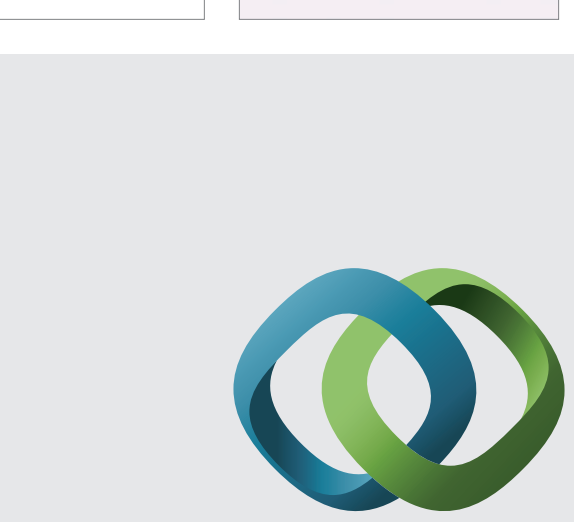

\section{Hindawi}

Submit your manuscripts at

http://www.hindawi.com
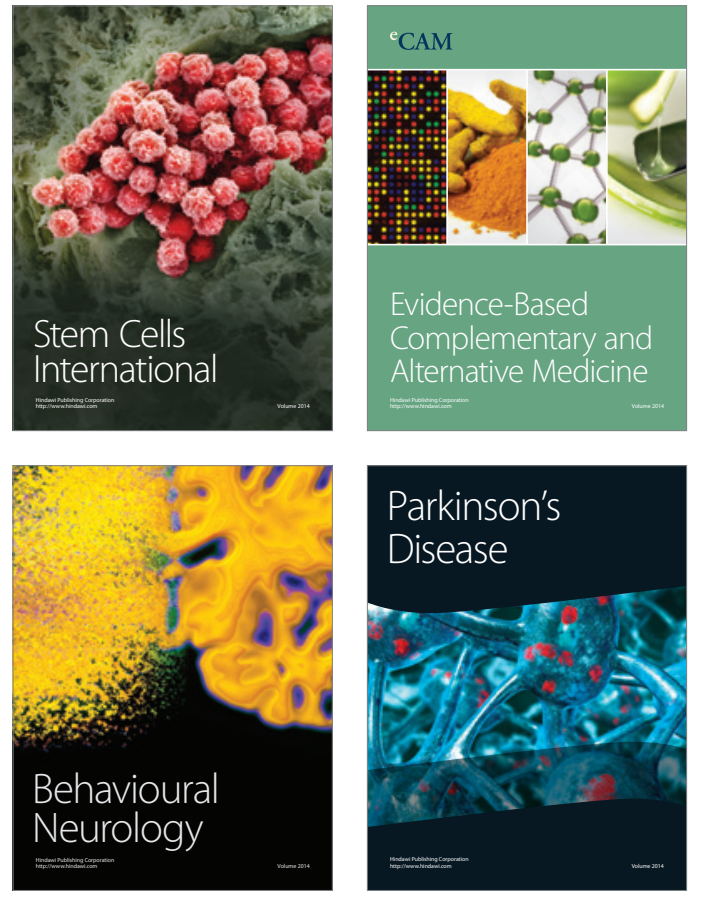
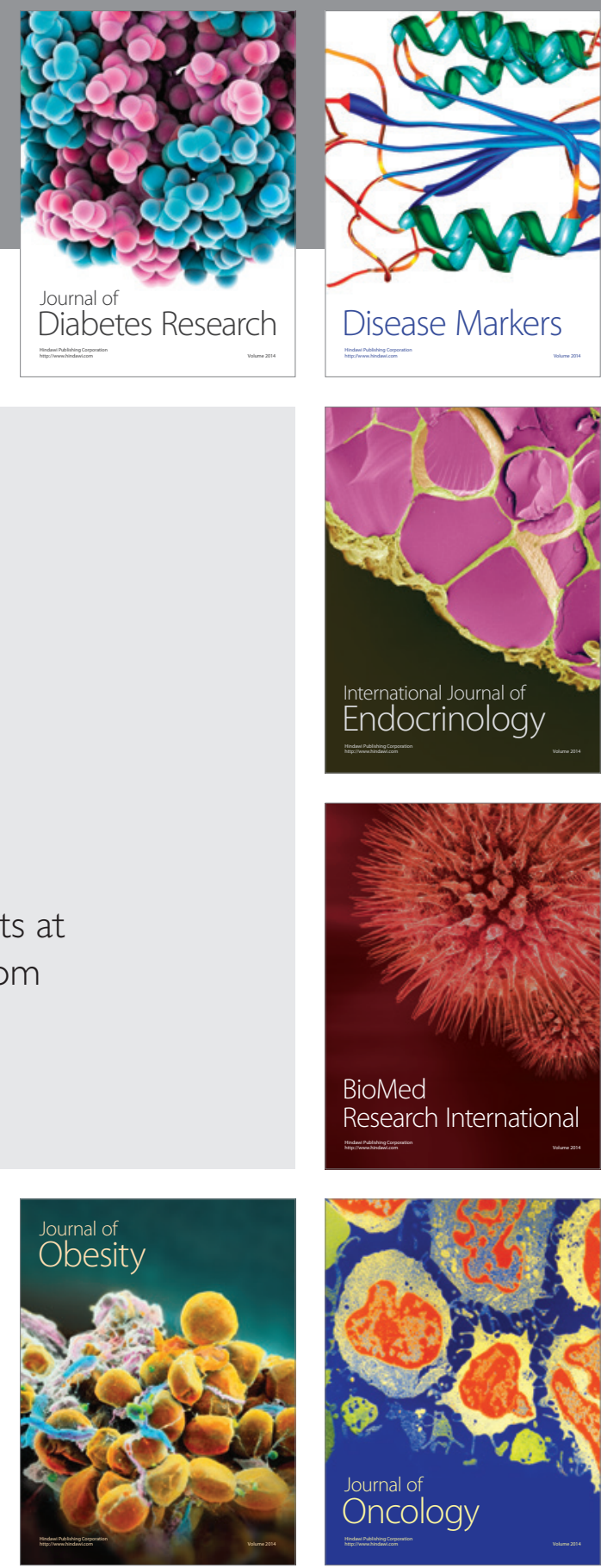

Disease Markers
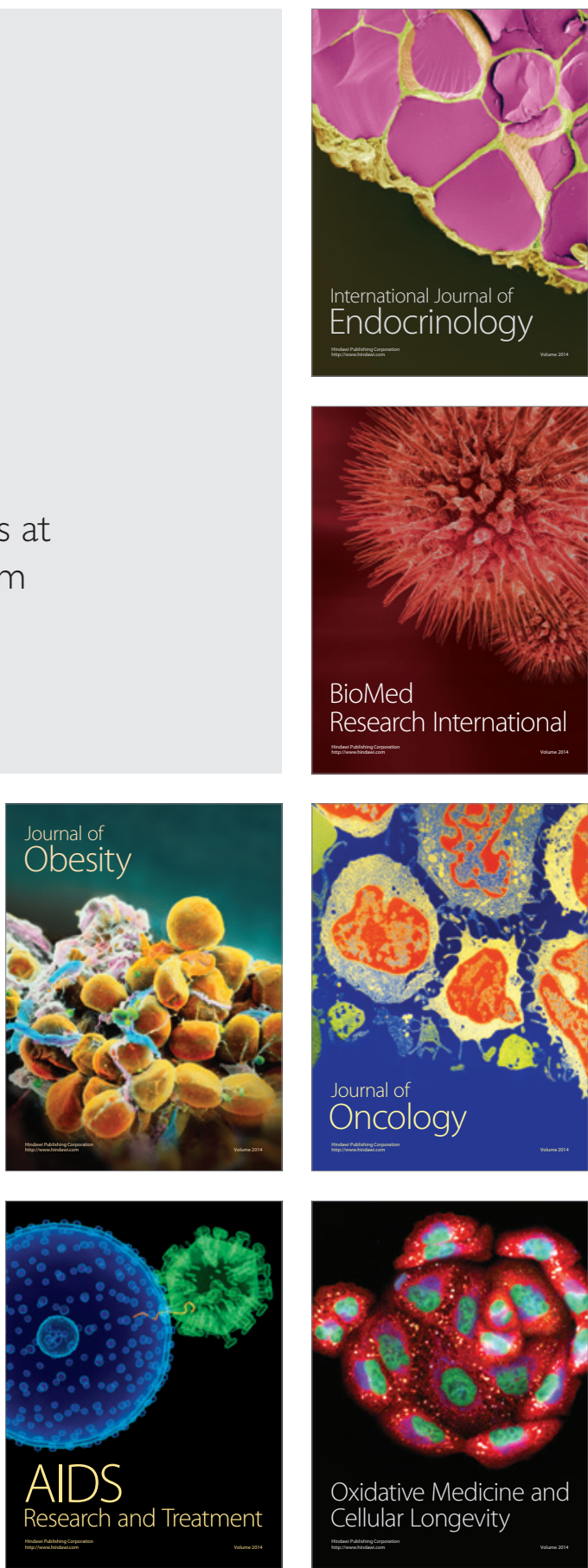